\title{
Serous cyst adenoma of the pancreas: appraisal of active surgical strategy before it causes problems
}

\author{
Ho Kyoung Hwang $\cdot$ Hyunki Kim • \\ Chang Moo Kang · Woo Jung Lee
}

Received: 21 August 2011/Accepted: 9 November 2011/Published online: 17 December 2011

(C) The Author(s) 2011. This article is published with open access at Springerlink.com

\begin{abstract}
Background Patients who are diagnosed with symptomatic or ambiguous serous cyst adenoma (SCA) need surgery. The purpose of this study is to suggest a potential management plan based on analysis of surgically treated SCAs. Methods Between August 1995 and December 2010, 38 patients with SCA were surgically treated. Data were analyzed retrospectively.

Results Among 38 patients, 28 were female and ten were male. Mean age was $49.6 \pm 14.1$ years, and five patients (13.2\%) were older than 65 years. Among the five patients, two were more than 70 years old. Seventeen patients (44.7\%) were symptomatic, and the rest $(21,55.3 \%)$ were incidentally found to have SCA. Twenty-seven patients underwent open pancreatectomy, and 11 patients received laparoscopic distal pancreatectomy. Mean tumor size was $4.4 \pm 2.8 \mathrm{~cm}$. Most asymptomatic patients of SCA had a left-sided pancreatic tumor and distal pancreatectomy with or without splenectomy were frequently performed with
\end{abstract}

H. K. Hwang · C. M. Kang $(\bowtie) \cdot$ W. J. Lee

Division of Hepatobiliary and Pancreas, Department of Surgery,

Yonsei University College of Medicine, Ludlow Faculty

Research Building \#204, 50 Yonsei-ro, Seodaemun-gu,

Seoul 120-752, Korea

e-mail: cmkang@yuhs.ac

H. K. Hwang · H. Kim · C. M. Kang · W. J. Lee

Pancreaticobiliary Cancer Clinic, Institute of Gastroenterology,

Yonsei University Health System, Seoul, Korea

H. K. Hwang · H. Kim · C. M. Kang

Young Yonsei Pancreatic Tumor Study Group, Seoul, Korea

H. Kim

Department of Pathology, Yonsei University College

of Medicine, Seoul, Korea short operative time and less blood transfusion $(P<0.05)$. Minimally invasive surgery was mostly applied to leftsided tumors less than $5 \mathrm{~cm}$ in size $(11 / 19$ vs. $0 / 6$, $P=0.029$ ). Combined resection of the right colon was performed in two patients $(5.3 \%)$ due to severe adhesion associated with large tumors. Significant association was noted between age and tumor size in asymptomatic patients (correlation coefficient $=0.541, R^{2}=0.293, P=0.014$ ). Postoperative pancreatic fistula was observed in five patients $(13.2 \%$, grade B) but could be managed conservatively. No mortality was found.

Conclusion Before SCA causes symptoms or grows larger than $5 \mathrm{~cm}$, an active surgical approach, such as minimally invasive surgery, needs to be considered.

Keywords Serous cyst adenoma - Surgery ·

Minimally invasive surgery $\cdot$ Observation

Neoplastic cysts account for 10-20\% of pancreatic cysts, and malignant cystic neoplasms account for about $1 \%$ of pancreatic malignant tumors [1, 2]. In 1978, Campagno and Oerterl [3] characterized for the first time 34 pancreatic serous cyst adenomas (SCAs). The histopathological characteristics include irregular thick fibrous bands without specific capsule, nerves, or fairly large blood vessels that course through or near the cystic tumor. Unlike mucinous cystic neoplasm or intraductal papillary mucinous neoplasm of the pancreas, SCA is generally considered a benign tumor with almost no malignant potential. Therefore, only expectant management with serial follow-up is provided, and surgery is not recommended in the absence of symptoms. Surgeons may need to wait until clinical symptoms related to SCA of the pancreas develop. However, the concept of this traditional approach to SCA of the 
pancreas was based on totally different clinical situations from those found today.

Recently, asymptomatic benign or borderline malignant cystic neoplasms of the pancreas are increasingly being detected on routine medical check-up, resulting from development of the socioeconomic conditions of the general population, increasing concern for personal health, and enhanced quality of axial imaging techniques $[4,5]$. In addition, advances in both surgical techniques of pancreatectomy and perioperative management have reduced perioperative morbidity and mortality following pancreatectomy to the level of general acceptance [6]. Furthermore, minimally invasive (laparoscopic or robotic) pancreatectomy is currently available and regarded as safe and effective in selected patients $[7,8]$. It is also beneficial in terms of quality of life. Therefore, it is thought that reconsideration of the rationale for the traditional approach to SCA of the pancreas is required. Many clinical elements supporting the rationale for the traditional expectant management have changed. Taking these facts into consideration, physicians must reexamine more appropriate ways of managing SCA of the pancreas.

In this study, we evaluated our institutional experience with surgically treated pancreatic SCA. Based on our experience, we suggest a potential strategy for managing SCA of the pancreas.

\section{Patients and methods}

We retrospectively reviewed the medical records of 38 patients who were diagnosed with serous cystadenoma of the pancreas and who underwent pancreatectomy between August 1995 and December 2010. In descriptive analysis, general characteristics of the patients, including age, gender, type of pancreatectomy, and perioperative outcomes, were evaluated. In comparative analysis, we divided the patients into two groups according to the presence of symptoms (symptomatic group and asymptomatic group), and clinicopathological variables of the two groups were compared. Categorical variables are expressed as frequency and percentage (\%). Continuous variables are expressed as mean \pm standard deviation. $\chi^{2}$ and Student $t$ tests were used where appropriate and linear regression was applied in correlating patient age to tumor size according to the presence of symptoms. $P$ values less than 0.05 were regarded as significant.

\section{Results}

General characteristics of resected SCAs

Among 38 patients, 28 were female and ten were male; mean age of all patients was $49.6 \pm 14.1$ years. Seventeen patients $(44.7 \%)$ presented with clinical symptoms, whereas the rest were incidentally found during routine medical check-up or evaluation of other, unrelated medical problems. Abdominal pain and discomfort were the most frequent symptoms $(n=11,64.7 \%)$, followed by indigestion $(n=6,35.3 \%)$. Seven patients $(18.4 \%)$ were associated with previous malignant disease: thyroid cancer $(n=2)$, breast cancer $(n=1)$, cervix cancer $(n=1)$, gastric cancer $(n=1)$, lung cancer $(n=1)$, and hepatoma $(n=1)$. Most tumors $(n=25,65.8 \%)$ were located on the left side of the pancreas (body and tail), and the rest on the pancreatic head portion. Tumor enucleation was done in five patients, conventional pancreatoduodenectomy in 5, and pylorus-preserving pancreatoduodenectomy in 4 , and distal pancreatectomy with splenectomy in 12 , and spleenpreserving distal pancreatectomy in 12 . Since 2005, our institution has been applying minimally invasive (laparoscopic and robotic) pancreatectomy to manage SCA located at the distal side of the pancreas. Especially when considering left-sided SCA, minimally invasive surgery was mostly applied to tumors less than $5 \mathrm{~cm}$ in size (11/19 versus $0 / 6, P=0.029$ ) (Table 1). Postoperative complications were noted in eight patients $(21.1 \%)$, and all could be managed conservatively. Postoperative pancreatic fistula was observed in five patients $(13.2 \%$, grade B), and delayed gastric emptying in one patient. Pneumonia with acute myocardial infarction and wound failure were each noted in one patient. No mortality was found in this series.

Potential clinical problems derived from SCA of the pancreas

First, symptoms were clinical problems for patients with SCA. Surgery was performed on 17 patients $(44.7 \%)$ who presented with clinical symptoms. Second, the patients with SCA larger than $5 \mathrm{~cm}$ in size lost the chance to receive minimally invasive surgery. All six patients (15.8\%) who had tumor larger than $5 \mathrm{~cm}$ in size underwent open distal pancreatectomy (Table 1). Third, older age was a clinical problem. Five patients $(13.2 \%)$ were older than 65 years. Among them, two patients were more than 70 years old, and three patients showed clinical symptoms. Finally, tumor adhesion to adjacent organ was a clinical

Table 1 Procedure pattern according to tumor size for left-sided SCA $(n=25)$

\begin{tabular}{lllll}
\hline & \multicolumn{2}{l}{ Tumor size } & $P$ value \\
\cline { 2 - 4 } & $<3 \mathrm{~cm}$ & $3-5 \mathrm{~cm}$ & $\geq 5 \mathrm{~cm}$ & \\
\hline Open $(n=14)$ & $3(60 \%)$ & $5(35.7 \%)$ & $6(100 \%)$ & 0.029 \\
MIS* $(n=11)$ & $2(40.0 \%)$ & $9(64.3 \%)$ & 0 & \\
\hline
\end{tabular}

* MIS minimally invasive surgery, including laparoscopic and robotic 
Table 2 Comparative analysis according to presence of symptoms

\begin{tabular}{|c|c|c|c|}
\hline & $\begin{array}{l}\text { Asymptomatic } \\
(n=21)\end{array}$ & $\begin{array}{l}\text { Symptomatic } \\
(n=17)\end{array}$ & $P$ value \\
\hline Age (years) & $47.9 \pm 12.6$ & $51.7 \pm 15.9$ & 0.416 \\
\hline Gender, $n(\%)$ & & & 0.726 \\
\hline Female & $15(71.4 \%)$ & $13(76.5 \%)$ & \\
\hline Male & $6(28.6 \%)$ & $4(23.5 \%)$ & \\
\hline Tumor size $(\mathrm{cm})$ & $3.6 \pm 1.9$ & $5.3 \pm 3.4$ & 0.091 \\
\hline Tumor location, $n(\%)$ & & & 0.005 \\
\hline Proximal & $3(14.3 \%)$ & $10(58.8 \%)$ & \\
\hline Distal & $18(85.7 \%)$ & $7(41.2 \%)$ & \\
\hline Surgery $1, n(\%)$ & & & 0.955 \\
\hline Open & $15(71.4 \%)$ & $12(70.6 \%)$ & \\
\hline MIS* & $6(28.6 \%)$ & $5(29.4 \%)$ & \\
\hline Surgery $2, n(\%)$ & & & 0.020 \\
\hline Enucleation & $3(14.3 \%)$ & $2(11.8 \%)$ & \\
\hline PD & 0 & $5(29.4 \%)$ & \\
\hline PPPD & $1(4.8 \%)$ & $3(17.6 \%)$ & \\
\hline DPS & $10(47.6 \%)$ & $2(11.8 \%)$ & \\
\hline DP-S & $7(33.3 \%)$ & $5(29.4 \%)$ & \\
\hline Operation time $(\min )$ & $203.6 \pm 86.8$ & $311.2 \pm 135.3$ & 0.009 \\
\hline Bleeding (ml) & $339.4 \pm 351.7$ & $662.5 \pm 780.5$ & 0.153 \\
\hline Transfusion & & & 0.003 \\
\hline No & $19(90.5 \%)$ & $8(47.1 \%)$ & \\
\hline Yes & $2(9.5 \%)$ & $9(52.9 \%)$ & \\
\hline LOH (day) & $12.2 \pm 6.1$ & $18.5 \pm 12.9$ & 0.059 \\
\hline Complication, $n(\%)$ & & & 0.736 \\
\hline No & $17(81 \%)$ & $13(76.5 \%)$ & \\
\hline Yes & $4(19 \%)$ & $4(23.5 \%)$ & \\
\hline
\end{tabular}

* MIS minimally invasive surgery, including laparoscopic and robotic $P D$ pancreatoduodenectomy, $P P P D$ pylorus-preserving pancreatoduodenectomy, DPS distal pancreatectomy with splenectomy, $D P-S$ distal pancreatectomy without splenectomy, $L O H$ length of hospital stay

problem in large tumors. In spite of its benign characteristics, combined resection of the right colon was performed in two patients $(5.3 \%)$ due to severe adhesion to large tumors.

Comparative analysis: asymptomatic

versus symptomatic SCA

On comparative analysis between symptomatic and asymptomatic SCA (Table 2), most asymptomatic patients of SCA had a left-sided pancreatic tumor, so distal pancreatectomy with or without splenectomy was more frequently performed $(P<0.05)$. Therefore, $1.5 \mathrm{~h}$ of operation time could be saved with asymptomatic patients $(P<0.05)$, and transfusion was less frequently given to asymptomatic patients $(P<0.05)$. Other clinical perioperative outcomes including estimated amount of intraoperative bleeding, and surgical complications were similar between the groups $(P>0.05)$. Interestingly, no correlation between patient age and tumor size was observed in the symptomatic patients $\left(P=0.597\right.$, correlation coefficient $=0.138, R^{2}=0.019$, Fig. 1A), while significant association was observed in the asymptomatic patients $(P=0.014$, correlation coefficient $=0.541, R^{2}=0.293$, Fig. 1B).

\section{Discussion}

In general, when managing SCA of the pancreas, most surgeons recommend observation with serial follow-up by means of axial imaging study as long as the tumor is not directly related to presenting symptoms. Unlike mucinous cystic tumors and intraductal papillary mucin-producing tumors of the pancreas, SCAs are considered benign with almost no malignant potential $[9,10]$. However, considering improvement in socioeconomic conditions, prolonged life expectancy, surgical techniques, and perioperative management, such a passive management strategy should be reevaluated for the following reasons: First, the prevalence of cancer in serous cystic neoplasm (SCN) is known to be about $3 \%$, and a recent literature review of serous cyst adenocarcinoma [10] reported that the median age of the patients was 68 years (range 53-85 years) with median tumor size of $11 \mathrm{~cm}$ (range $2.5-11 \mathrm{~cm}$ ). This suggests that even SCNs might eventually progress to large malignant tumors in the elderly when not treated appropriately. Second, Tseng et al. [11] recently estimated the growth rate of SCAs based on serial axial imaging study. They observed that tumors smaller than $4 \mathrm{~cm}$ at presentation grew slowly (only about $0.12 \mathrm{~cm} /$ year), whereas those larger than $4 \mathrm{~cm}$ at presentation grew much faster $(1.6 \mathrm{~cm} /$ year $)$ and were more likely to develop symptoms. This suggests that tumor biology may be different according to tumor size, and pancreatic SCNs seem to aggressively transform as they grow. Our current data also seem to indirectly support their findings. In the present study, asymptomatic SCA patients showed significant correlation between age and tumor size (Fig. 1B), suggesting that asymptomatic SCA, if not treated, may indolently progress to large size in elderly patients. In addition, applying a minimally invasive approach to large tumors (more than $5 \mathrm{~cm}$ ) may be more difficult. In our series, two patients underwent combined colon resection due to severe adhesion to large SCA ( 9.5 and $10 \mathrm{~cm}$, respectively), and one of them was more than 70 years old. If SCA of the pancreas is not treated properly in time, clinical problems such as new symptoms or malignant degeneration may develop as patients grow older. In such cases, it would be more difficult to decide a surgical approach because 

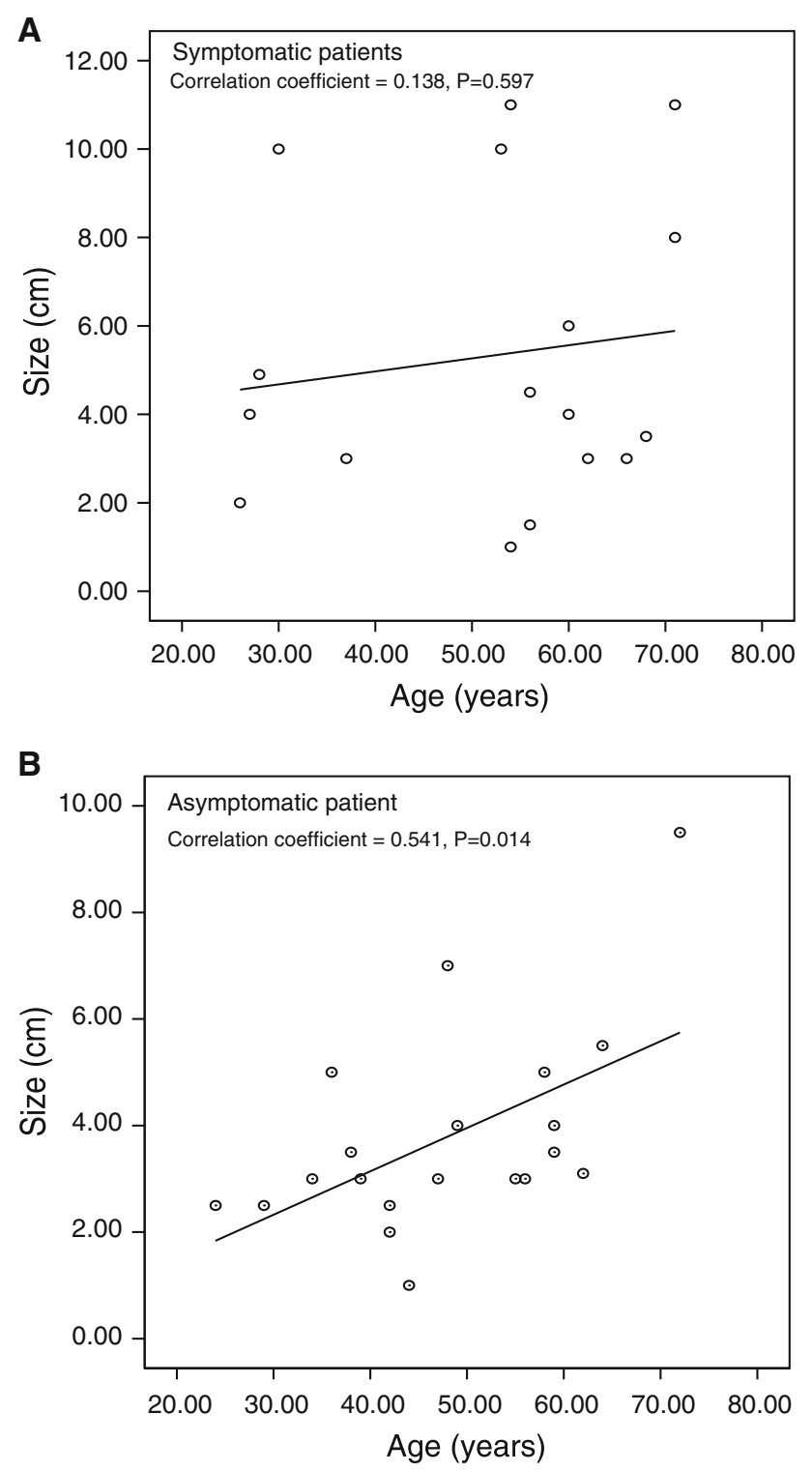

Fig. 1 Correlation between age and tumor size according to presence of symptoms

comorbidity related to patient age and large tumor size would make clinical situations more complicated. Considering that SCAs are usually benign, patients and surgeons need to avoid such complicated clinical settings.

In the past, it was thought that pancreatectomy should be avoided as much as possible due to its significant morbidity and potential mortality following pancreatectomy. However, operative morbidity and mortality have been reduced to generally acceptable ranges due to recent advances in surgical techniques and perioperative management, including interventional radiology, as well as increased surgical experience [12,13]. It is reported that high-volume centers can now perform pancreatectomy very safely [6-8, 14]. Our study also showed no mortality, and about $20 \%$ of the complications (including $13.2 \%$ of grade B postoperative pancreatic fistula) were successfully treated by conservative management. This suggests that pancreatectomy for managing SCA is a safe and reliable procedure. In addition, minimally invasive (laparoscopic and robotic) distal pancreatectomy with or without splenectomy is now regarded as a safe and effective surgical modality in managing benign and borderline malignant pancreatic tumors $[15,16]$. Even laparoscopic pancreatoduodenectomy is also thought to be safe in expert hands [17]. At our institute, application of minimally invasive distal pancreatectomy to left-sided SCAs has been increasing since 2005. On comparative analysis, left-sided pancreatic tumor was more frequently found in asymptomatic patients, and left-sided pancreatectomy was performed without increased perioperative risk in asymptomatic patients (Table 2). Minimally invasive approach is increasingly considered for asymptomatic left-sided SCA. SCN tends to become a large symptomatic tumor in the end and can create difficult clinical situations, such as open pancreatectomy, age-related comorbidity, and combined organ resection in spite of its benign characteristics. Thus, timely surgical intervention with either conventional open surgery or minimally invasive surgery is a reasonable strategy in current clinical practice. Based on the biologic properties of SCA and our experience, we suggest a potential strategy for managing SCA of the pancreas (Fig. 2). When a tumor is directly related to presenting clinical symptoms, pancreatectomy should be considered regardless of tumor size. In contrast, it may be better to serially follow an asymptomatic small SCA tumor less than $3 \mathrm{~cm}$. However, in case of a tumor between 3 and $5 \mathrm{~cm}$, minimally invasive pancreatectomy needs to be actively considered for wellselected left-sided SCA as it may grow indolently and then create difficult clinical problems. Although laparoscopic or robotic distal pancreatectomy with or without splenectomy is frequently and safely performed, application of this procedure should be cautiously considered by an expert at a high-volume center. If the tumor continues to grow or new clinical symptoms develop, surgery should be considered during the serial follow-up with the patient's full consent and knowledge of the potential risk of progression and clinical problems.

Considering patient social activity and the potential morbidity of pancreatic resection, pancreatectomy for mostly benign tumors should be avoided. However, when choosing the traditional approach for asymptomatic SCA, surgeons may need to take the following factors into consideration: potential risk of pancreatectomy with older age and practical issues related to long-term follow-up, such as cost-benefit effectiveness and patient compliance. Recently, minimally invasive pancreatectomy has been generally regarded as a safe and effective treatment 
Fig. 2 Suggested surgical approach for serous cyst adenoma. $C T$ computed tomography; MRI magnetic resonance imaging; EUS endoscopic ultrasound. *A minimally invasive approach can be considered according to the surgeon's experience, technique, and preference

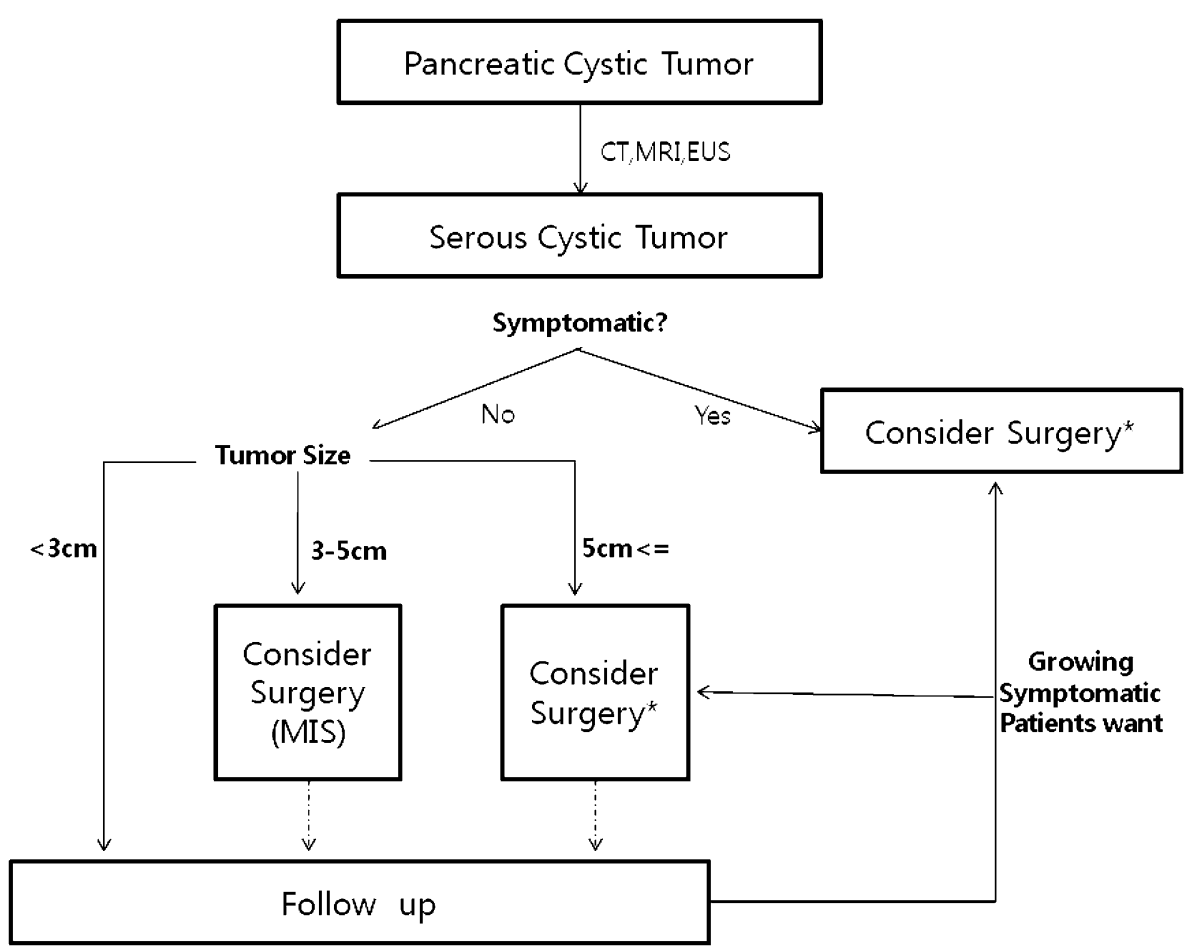

modality for benign and borderline malignant tumors. According to our results, large symptomatic tumors in need of surgical intervention are usually found in elderly patients. These elderly patients might have less chance for minimally invasive pancreatectomy, and there might be potential morbidity related to old age, which makes clinical situations more complicated. Tseng et al. [11] described the relationship between tumor size and speed of tumor growth, but no other study has presented data on the relationship between age and speed of tumor growth. A welldesigned prospective cohort study needs to be conducted for the evidence-based surgical decision in asymptomatic SCA of the pancreas.

In summary, SCA of the pancreas is rare but is expected to be detected more frequently due to easier access to medical care and improvement in pancreatic imaging study. According to previous studies and our surgical experience, the natural course of SCA is thought to be related to large symptomatic tumors or malignant degeneration at older age. Recently, open and minimally invasive pancreatectomy has been safely performed even in asymptomatic patients. Timely and appropriate surgical intervention such as minimally invasive surgery needs to be actively considered before pancreatic SCA causes clinical problems.

Disclosures Authors Ho Kyoung Hwang, Hyun Ki Kim, Chang Moo Kang, and Woo Jung Lee have no conflicts of interest or financial ties to disclose.
Open Access This article is distributed under the terms of the Creative Commons Attribution Noncommercial License which permits any noncommercial use, distribution, and reproduction in any medium, provided the original author(s) and source are credited.

\section{References}

1. ReMine SG, Frey D, Rossi RL, Munson JL, Braasch JW (1987) Cystic neoplasms of the pancreas. Arch Surg 122:443-446

2. Becker WF, Welsh RA, Pratt HS (1965) Cystadenoma and cystadenocarcinoma of the pancreas. Ann Surg 161:845-863

3. Compagno J, Oertel J (1978) Microcystic adenomas of the pancreas (glycogenrich cystadenomas): a clinicopathologic study of 34 cases. Am J Clin Pathol 69:289-298

4. del Fernandez-Castillo C, Targarona J, Thayer SP, Rattner DW, Brugge WR, Warshaw AL (2003) Incidental pancreatic cysts: clinicopathologic characteristics and comparison with symptomatic patients. Arch Surg 138:423-427 discussion 433-424

5. Sahani D, Prasad S, Saini S, Mueller P (2002) Cystic pancreatic neoplasms evaluation by $\mathrm{CT}$ and magnetic resonance cholangiopancreatography. Gastrointest Endosc Clin North Am 12:657-672

6. Birkmeyer JD, Warshaw AL, Finlayson SR, Grove MR, Tosteson AN (1999) Relationship between hospital volume and late survival after pancreaticoduodenectomy. Surgery 126:178-183

7. Kim SC, Park KT, Hwang JW, Shin HC, Lee SS, Seo DW, Lee SK, Kim MH, Han DJ (2008) Comparative analysis of clinical outcomes for laparoscopic distal pancreatic resection and open distal pancreatic resection at a single institution. Surg Endosc 22:2261-2268

8. Song KB, Kim SC, Park JB, Kim YH, Jung YS, Kim MH, Lee SK, Seo DW, Lee SS, Park do H, Han DJ (2011) Single-center experience of laparoscopic left pancreatic resection in 359 consecutive patients: changing the surgical paradigm of left pancreatic resection. Surg Endosc 25:3364-3372 
9. Galanis C, Zamani A, Cameron JL, Campbell KA, Lillemoe KD, Caparrelli D, Chang D, Hruban RH, Yeo CJ (2007) Resected serous cystic neoplasms of the pancreas: a review of 158 patients with recommendations for treatment. J Gastrointest Surg 11: 820-826

10. King JC, Ng TT, White SC, Cortina G, Reber HA, Hines OJ (2009) Pancreatic serous cystadenocarcinoma: a case report and review of the literature. J Gastrointest Surg 13:1864-1868

11. Tseng JF, Warshaw AL, Sahani DV, Lauwers GY, Rattner DW, del Fernandez-Castillo C (2005) Serous cystadenoma of the pancreas: tumor growth rates and recommendations for treatment. Ann Surg 242:413-419 discussion 419-421

12. Sohn TA, Yeo CJ, Cameron JL, Geschwind JF, Mitchell SE, Venbrux AC, Lillemoe KD (2003) Pancreaticoduodenectomy: role of interventional radiologists in managing patients and complications. J Gastrointest Surg 7:209-219

13. Yekebas EF, Wolfram L, Cataldegirmen G, Habermann CR, Bogoevski D, Koenig AM, Kaifi J, Schurr PG, Bubenheim M,
Nolte-Ernsting C, Adam G, Izbicki JR (2007) Postpancreatectomy hemorrhage: diagnosis and treatment: an analysis in 1669 consecutive pancreatic resections. Ann Surg 246:269-280

14. Balcom JHt, Rattner DW, Warshaw AL, Chang Y, del Fernandez-Castillo C (2001) Ten-year experience with 733 pancreatic resections: changing indications, older patients, and decreasing length of hospitalization. Arch Surg 136:391-398

15. Giulianotti PC, Sbrana F, Bianco FM, Elli EF, Shah G, Addeo P, Caravaglios G, Coratti A (2010) Robot-assisted laparoscopic pancreatic surgery: single-surgeon experience. Surg Endosc 24: $1646-1657$

16. Rosok BI, Marangos IP, Kazaryan AM, Rosseland AR, Buanes T, Mathisen O, Edwin B (2010) Single-centre experience of laparoscopic pancreatic surgery. Br J Surg 97:902-909

17. Gagner M, Palermo M (2009) Laparoscopic Whipple procedure: review of the literature. J Hepatobiliary Pancreat Surg 16: $726-730$ 